\title{
Margaret McCartney: Regulation doesn’t guarantee safety
}

\author{
Margaret McCartney general practitioner, Glasgow
}

The NHS does bad things. A young man with learning disability drowned in a bath while in its care. Subcultures have existed that have ignored cries of pain. The NHS has covered up events leading to deaths rather than being open. The chief inspector of general practice in England, Steve Field, has said that he's ashamed of his profession and that we haven't dealt with our failings. ${ }^{1}$ There are two responses to all of this.

The first is pain, despair, despondency, helplessness-along with responsibility, anger, and sadness. This is often my response, which makes me miserable and distressed and changes nothing. Our systems of regulation encourage a

blame-guilt-shame-fear cycle, even though this fails to help and may cause net harm to patients and doctors. Bad doctors, nurses, and other healthcare staff have always existed. Realistically, they always will.

The second response is to consider this a humanitarian, sociological, and anthropological long game. The NHS is the best of moral humanity. It's staffed by humans who will sometimes behave wonderfully, sometimes not. They make mistakes and often do badly under pressure because they are fallible, tired, overwhelmed, and anxious. Some are almost always marvellous. Some are occasionally or repeatedly unpleasant. A few are truly awful. And half of us are below average. The key is for the system to encourage the best in people while protecting patients from the worst we are capable of either by intention or, far more commonly, through human error.

The blame-guilt-shame-fear cycle, beloved of the media, politicians, and senior medical leaders, makes it hard to talk about mistakes. The General Medical Council's investigation process is long, slow, and inefficient. Expensive appraisal doesn't reliably find poor practice. The Care Quality Commission, which stimulates dread and anxiety, is blamed for sucking up resources and for displaying the kind of behaviours it's meant to expunge.
We should have sociologists, anthropologists, and psychologists working with healthcare professionals and patients to assess the real life evidence about what could make the NHS safer and about what doesn't work. Staffing, appointment length, technology, relationships-we should test, share, and be open about what makes the NHS safer and what does harm. We need fast and robust investigation and the means to remove the rare but harmful individuals who do unthinking damage.

Professionals need to work in cultures and systems that are designed to make us less likely to fail. I have 12 minutes for a person with an acute problem, a background of multimorbidity, and a possible new diagnosis of depression. Despite starting earlier and finishing later, I still fail every single day to give the best care I could. We need to stop pretending that regulation will help with this.

Competing interests: I have read and understood BMJ policy on declaration of interests and declare the following interests: I'm an NHS GP partner, with income partly dependent on Quality and Outcomes Framework points. I've written two books and earn from broadcast and written freelance journalism. I'm an unpaid patron of Healthwatch. I make a monthly donation to Keep Our NHS Public. I'm a member of Medact. I'm occasionally paid for time, travel, and accommodation to give talks or have locum fees paid to allow me to give talks but never for any drug or public relations company. I was elected to the national council of the Royal College of General Practitioners in 2013 and am chair of its standing group on overdiagnosis. I have invested a small amount of money in a social enterprise, Who Made Your Pants?

Provenance and peer review: Commissioned; not externally peer reviewed.

Follow Margaret on Twitter, @mgtmccartney

1 O'Dowd A. BMA calls for chief inspector of general practice to resign. BMJ 2015;351:h6903.

Cite this as: BMJ 2016;352:i96

๑ BMJ Publishing Group Ltd 2016 